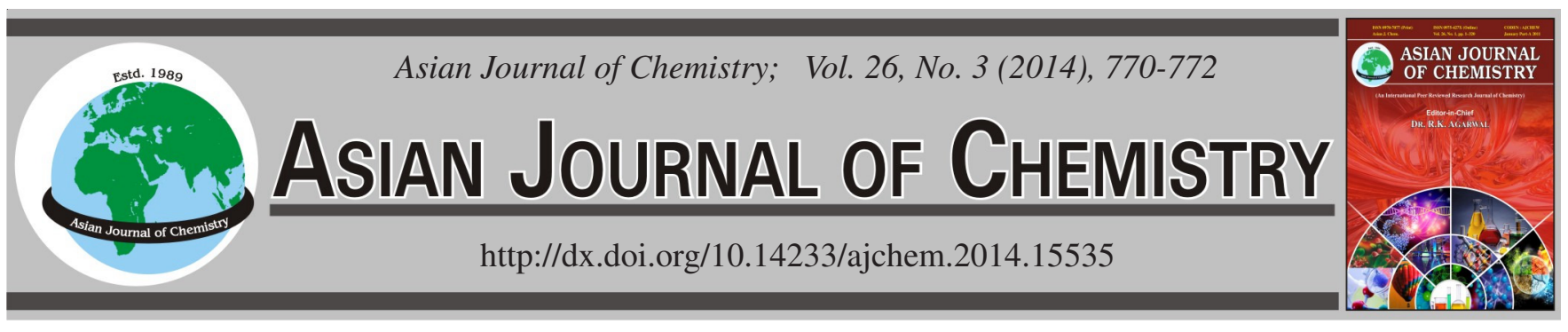

\title{
Formulation and Evaluation of Ethyl Cellulose Coated Microcapsules of Glibenclamide for Controlled Release
}

P. Dwarakanadha Reddy ${ }^{*}$ A. Surya Prakash, Shaik Shafi, R. Usha Sree, T. Thippa Reddy, D. Swarnalatha and S. Prasanthi

Department of Pharmaceutics, Annamacharya College of Pharmacy, Rajampet-516 126, India

*Corresponding author: E-mail: dwarak2001@yahoo.co.in

\begin{abstract}
Microencapsulation has been widely employed in the design of controlled release dosage forms. Glibenclamide has short biological halflife of 4-6 h and is eliminated rapidly. Therefore control release products are needed for glibenclamide to prolong its duration of action and to improve patience compliance. In the present investigation, studies were carried out on microencapsulation of glibenclamide by ethyl cellulose as a polymer with an objective of developing glibenclamide micro capsules for oral controlled release because this drug require to control release formulation for better control of hypoglycemia and to enhance their therapeutic efficacy and for improved patient compliance. Microcapsules were successfully prepared by an emulsification solvent evaporation method. All the microcapsules prepared were evaluated for size and size distribution, drug content of microcapsules, microencapsulation efficiency, wall thickness, dissolution rate kinetics and mechanism. The yields were varies from 95-98 \% and encapsulation efficacy is maximum. The FTIR studies used to confirmed the interaction between drug and polymer. The SEM photograph of microcapsules confirmed good spheres and smooth surface.
\end{abstract}

Keywords: Glibenclamide, Ethyl cellulose, Microcapsules, Controlled drug delivery.

\section{INTRODUCTION}

Controlled drug delivery is a topic of current interest in pharmaceutical technology and industry. In recent years considerable attention has been focused on the development of new drug delivery system known as controlled release drug delivery system. Controlled release drug delivery systems are aimed at controlling the rate of drug delivery, sustaining the duration of activity and targeting the drug to a tissue, have been used to overcome the shortcoming of conventional drug formulations. Micro-encapsulation is a process in which tiny particles or droplets are surrounded by a coating to give small capsules many useful properties ${ }^{1}$. In a relatively simplistic form, a microcapsule is a small sphere with a uniform wall around it. The material inside the microcapsule is referred to as the core, internal phase, or fill, whereas the wall is sometimes called a shell, coating, or membrane. Most microcapsules have diameters between a few micrometers and a few millimeters.

Diabetes mellitus, often simply referred to as diabetes, is a group of metabolic diseases in which a person has high blood sugar, either because the body does not produce enough insulin, or because cells do not respond to the insulin that is produced. This high blood sugar produces the classical symptoms of polyuria (frequent urination), polydipsia (increased thirst) and polyphagia (increased hunger). In the late 1970s both WHO and the National Diabetes Data Group produced new diagnostic criteria and a new classification system for diabetes mellitus. This brought order to a chaotic situation in which nomenclature varied and diagnostic criteria showed enormous variations using different oral glucose loads. In 1985 WHO slightly modified their criteria to coincide more closely with the NDDG values.

Glibenclamide is an effective oral anti-diabetic agent that belongs to the sulphonylurea drug class. Pharmacological studies indicate that glibenclamide improves glycemic control while reducing circulating insulin level ${ }^{2}$. Glibenclamide has short biological half-life of 4-6 $\mathrm{h}$ and is eliminated rapidly ${ }^{3}$.

Therefore control release products are needed glibenclamide to prolong its duration of action and to improve patience compliance. There are few reports on the formulation of glibenclamide employing coated granules and matrix tablets. The drug also causes gastro intestinal disturbances such gastric pain, constipation, nausea and vomiting if present in larger concentration in G.I. tract. Controlled release formulation is also needed for glibenclamide for better control of blood glucose levels to prevent hypoglycemia and enhance clinical efficacy, to reduce G.I. disturbances and to enhance patient compliance. No controlled (microcapsules) release formulations of glibenclamide are available commercially ${ }^{4}$. 


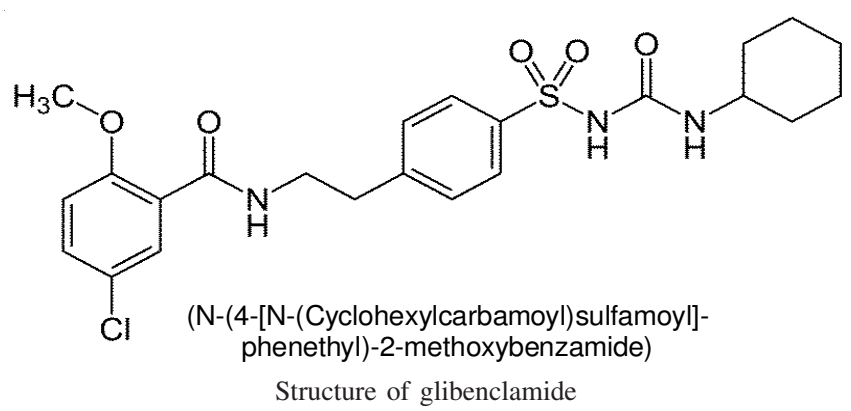

EXPERIMENTAL

Glibenclamide was a gift sample from Dr. Reddy's Laboratories, Hyderabad and Ethyl Cellulose (BDH; having an ethoxyl content of $47.5 \%$ by weight and viscosity of $22 \mathrm{cps}$ in a $5 \%$ concentration by weight, in a 80:20 tolune-ethanol solution at $25^{\circ} \mathrm{C}$ ) from (Richer chemicals Pvt. LTD. Hyderabad, India), Sodium carboxy methyl cellulose (sodium CMC having a viscosity of $1500-3000 \mathrm{cps}$ of a $1 \%$ solution at $25^{\circ} \mathrm{C}$ ), methanol from qualigens and All other materials used were of pharmacopoeia grade.

Drug-polymer interactions were studied by FTIR spectroscopy. The spectra were recorded for pure drug and drug loaded microspheres using FTIR SHIMADZU, Japan. Samples were prepared in $\mathrm{KBr}$ disks. The scanning range was $4000-400 \mathrm{~cm}^{-1}$ and the resolution was $2 \mathrm{~cm}^{-1}$.

Preparation of microcapsules: Studies are carried out on microencapsulation of glibenclamide employing ethyl cellulose characterization and evaluation of the resulting microcapsules for controlled drug release. An emulsificationsolvent evaporation method was tried to prepare ethyl cellulose microcapsules ${ }^{5}$. Polymer ethyl cellulose $(2 \mathrm{~g})$ was dissolved in chloroform $(50 \mathrm{~mL})$ to form a homogeneous solution. Core material, i.e. glibenclamide $(0.8 \mathrm{~g})$ was added to the polymer solution $(5 \mathrm{~mL})$ and mixed thoroughly. The resulting mixture was then added in a thin stream to $200 \mathrm{~mL}$ of an aqueous mucilage of sodium CMC $(0.5 \% \mathrm{w} / \mathrm{v})$ contained in a $500 \mathrm{~mL}$ beaker while stirring at $1000 \mathrm{rpm}$ to emulsify the added dispersion as fine droplets. A Remi medium duty stirrer with speed meter (REMI Model "MLH-DLX MS-RPM 0 to 3000) was used for stirring. The solvent, chloroform was then removed by continuous stirring at room temperature $\left(28{ }^{\circ} \mathrm{C}\right)$ for $3 \mathrm{~h}$ to produce spherical microcapsules. The microcapsules were collected by vacuum filtration and washed repeatedly with water. The product was then air dried to obtain discrete microcapsules. Three batches of microcapsules of glibenclamide are prepared.

The FTIR spectroscopy of pure drug glibenclamide shows prominent peaks at 3354.32, 1652.52, 1628.12, 1161.19, 1035.31, $1591.34,2974.54,2920.14,1332.86$ and $666.68 \mathrm{~cm}^{-1}$ due to $\mathrm{NH}$-stretching $\mathrm{C}=\mathrm{O}$ stretching, $\mathrm{NH}$-bending, $\mathrm{C}-\mathrm{N}$ stretching (aliphatic), $\mathrm{C}-\mathrm{N}$ stretching (aromatic), $\mathrm{C}=\mathrm{C}$ stretching (aromatic), $-\mathrm{CH}_{3}$ stretching, $\mathrm{C}-\mathrm{H}$ stretching (aliphatic), $\mathrm{S}=\mathrm{O}$ stretching, $\mathrm{C}-\mathrm{H}$ bending (aliphatic) respectively. The $\mathrm{C}-\mathrm{Cl}$ group is shown at $722.75 \mathrm{~cm}^{-1}$ and the $\mathrm{C}-\mathrm{O}$ stretching shown at $1100.59 \mathrm{~cm}^{-1}$ which confirming the position of $\mathrm{OCH}_{3}$. The IR spectrum of formulation also showed peaks in same region confirming no drug polymer interaction.
Size and size distribution analysis: Distribution analysis, different sizes in a batch were separated by sieving using range of standard sieves.

Estimation of glibenclamide content in the microcapsules: Glibenclamide content of the microcapsules was estimated by UV spectrophotometric method based on the measurement of absorbance at $269 \mathrm{~nm}$ in phosphate buffer of $\mathrm{pH}$ 7.4. From each batch of microcapsules, four samples of $25 \mathrm{mg}$ each were taken into $25 \mathrm{~mL}$ volumetric flasks and $20 \mathrm{~mL}$ methanol were added to each. The mixture was shaken thoroughly for about $0.5 \mathrm{~h}$ to extract the glibenclamide from the microcapsules. The solution was then made up to volume with methanol. The methanolic solution was subsequently diluted suitably with phosphate buffer of $\mathrm{pH} 7.4$ and assayed for glibenclamide by measuring absorbance at $269 \mathrm{~nm}$. Glibenclamide content of the microcapsules was calculated using the calibration curve.

Microencapsulation efficiency: Microencapsulation efficiency was calculated using the equation.

$$
\text { Encapsulation efficiency }=\frac{\text { Estimated drug content }(\%)}{\text { Theoretical drug content }(\%)} \times 100
$$

Wall thickness: As the microcapsules are spherical, the average thickness of the wall that surrounds the drug particles was determined by the method of Si-Nag et al. ${ }^{6}$ using the equation.

$$
\mathrm{h}=\left[\overline{\mathrm{r}}(1-\mathrm{p}) \mathrm{d} 1 / 3\left[\mathrm{pd}_{2}+(1-\mathrm{p}) \mathrm{d} 1\right]\right.
$$

where $\mathrm{h}=$ is the wall thickness; $\mathrm{r}=$ is the mean radius of the microcapsules; $\mathrm{dl}=$ is the density of the core material; $\mathrm{d}_{2}=$ is the density of the coat material and $p=$ is the proportion of the medicament in the microcapsules.

Drug release study on glibenclamide microcapsules: Release of glibenclamide from the microcapsules prepared was studied in phosphate buffer of $\mathrm{pH} 7.4$ (900 mL) using an eight station dissolution rate test apparatus with a paddle stirrer at $50 \mathrm{rpm}$ and $37 \pm 0.5^{\circ} \mathrm{C}$. A sample of microcapsules equivalent to $10 \mathrm{mg}$ of glibenclamide were used in each test. Samples of dissolution fluid $(5 \mathrm{~mL})$ were withdrawn through a filter $(0.45 \mu)$ at different time intervals and were assayed at $269 \mathrm{~nm}$ for glibenclamide using a Schimadzu UV-1400 double beam spectrophotometer. The sample $(5 \mathrm{~mL})$ taken at each sampling time was replaced with fresh dissolution medium $(5 \mathrm{~mL})$. The drug release experiments were conducted in triplicate $^{7}$ data were shown in Table-1 and Fig. 2.

Scanning electron microscopy: The microcapsules prepared were observed under a scanning electron microscope (Jeol JXA 8100 Ltd., Tokyo, Japan). The samples were fixed on a brass stub using double sided sticking tape and then gold coated in vacuum by a sputter coater. Scanning electron microscopy photographs (Fig. 1) showed that the microcapsules are spherical with smooth surface and completely covered with the polymer coat in all the cases.

\section{RESULTS AND DISCUSSION}

The overall objective of the present investigation is to design controlled release formulations in the form of microcapsules of glibenclamide anti diabetic BCS Class II 


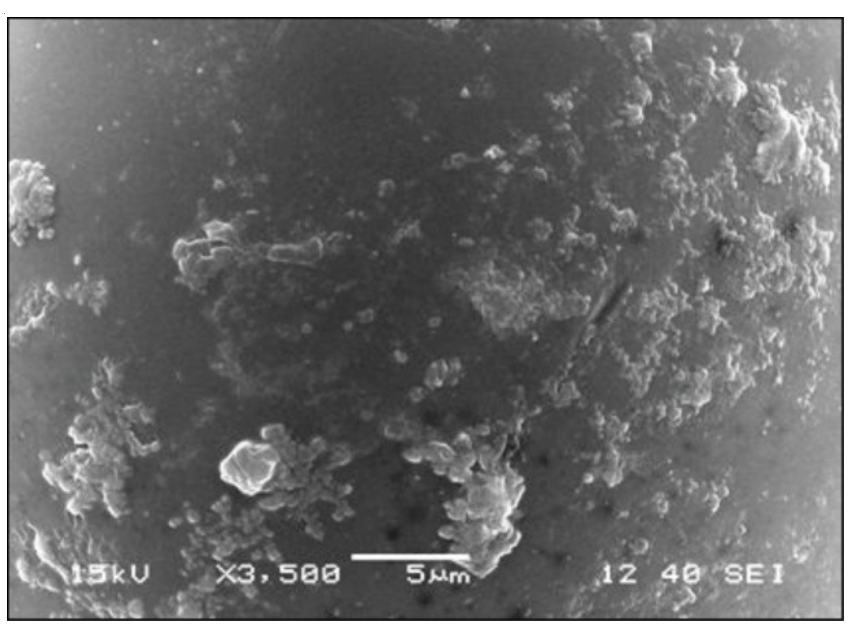

Fig. 1. Scanning electron micrograph of glibenclamide microcapsules with ethyl cellulose

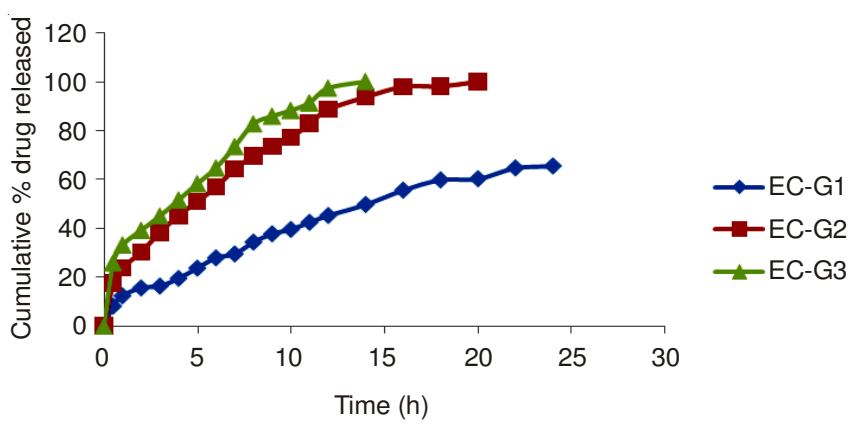

Fig. 2. Drug release profiles of ethyl cellulose microcapsules prepared employing glibenclamide

\begin{tabular}{|c|c|c|c|}
\hline $\begin{array}{r}\text { DR } \\
\text { MICROCAP }\end{array}$ & $\begin{array}{l}\text { TAB } \\
\text { ELEASE OF ET } \\
\text { SS PREPARED }\end{array}$ & $\begin{array}{l}\text { E-1 } \\
\text { IYL CELLULC } \\
\text { MPLOYING G }\end{array}$ & $\begin{array}{l}\text { (EC) } \\
\text { ENCLAMIDE }\end{array}$ \\
\hline \multirow{2}{*}{ Time (h) } & \multicolumn{3}{|c|}{ Cumulative percent glibenclamide released } \\
\hline & EC-G1 & EC-G2 & EC-G3 \\
\hline 0 & 0 & 0 & 0 \\
\hline 0.5 & $8.16 \pm 1.30$ & $17.49 \pm 1.34$ & $25.91 \pm 0.88$ \\
\hline 1 & $12.35 \pm 1.59$ & $23.74 \pm 1.54$ & $33.19 \pm 0.66$ \\
\hline 2 & $15.55 \pm 1.65$ & $30.30 \pm 1.65$ & $39.19 \pm 0.156$ \\
\hline 3 & $16.32 \pm 1.89$ & $38.34 \pm 1.88$ & $44.98 \pm 1.65$ \\
\hline 4 & $19.45 \pm 0.77$ & $45.28 \pm 0.78$ & $51.57 \pm 1.88$ \\
\hline 5 & $23.65 \pm 0.49$ & $50.94 \pm 0.43$ & $58.21 \pm 1.43$ \\
\hline 6 & $27.86 \pm 0.80$ & $56.89 \pm 0.87$ & $64.68 \pm 1.28$ \\
\hline 7 & $29.45 \pm 1.33$ & $64.17 \pm 1.32$ & $73.40 \pm 0.82$ \\
\hline 8 & $34.25 \pm 0.87$ & $69.57 \pm 0.88$ & $82.68 \pm 0.72$ \\
\hline 9 & $37.65 \pm 0.75$ & $73.53 \pm 0.76$ & $85.88 \pm 0.72$ \\
\hline 10 & $39.45 \pm 0.80$ & $77.11 \pm 1.22$ & $88.18 \pm 0.72$ \\
\hline 11 & $42.35 \pm 0.75$ & $82.81 \pm 1.63$ & $91.28 \pm 1.42$ \\
\hline 12 & $45.12 \pm 1.20$ & $88.64 \pm 0.66$ & $97.32 \pm 1.68$ \\
\hline 14 & $49.62 \pm 1.60$ & $93.70 \pm 0.56$ & $100.00 \pm 0.76$ \\
\hline 16 & $55.45 \pm 0.68$ & $97.91 \pm 1.55$ & - \\
\hline 18 & $59.65 \pm 0.56$ & $98.12 \pm 1.42$ & - \\
\hline 20 & $60.12 \pm 0.56$ & $100.00 \pm 1.42$ & - \\
\hline 22 & $64.54 \pm 0.56$ & - & - \\
\hline 24 & $65.34 \pm 0.56$ & - & - \\
\hline
\end{tabular}

drug. Because low aqueous solubility and dissolution rate, these BCS Class II drugs pose problems in the design of controlled release products. When these drugs are coated with or embeded in water impervious polymers and materials in the design of controlled release products, the drug release rates are much reduced leading to inadequate blood levels and reduced bioavailability and therapeutic efficacy. Glibenclamide release from the microcapsules depended on the composition of the core used. With polymer drug release from microencapsulated, the release rates were improved and release was slow, controlled and complete (nearly $100 \%$ ) with the polymer. Size and size distribution for all microcapsules having uniform size and accurate. Drug content of microcapsules having $98.02 \%$ maximum in all microcapsules. Microencapsulation efficiency, wall thickness and dissolution rate kinetics and mechanism were good in all cases of microcapsules.

Stability studies: No visible changes were observed in microcapsules after storage. Drug content and drug release from the microcapsules tested were evaluated before and after storage. No significant difference $(\mathrm{P}>0.05)$ was observed in the per cent drug content before and after storage for in each case.

\section{Conclusion}

The significant achievement of the present investigation is development of controlled release formulations of poorly soluble glibenclamide of BCS class II drug employing ethyl cellulose which is not possible with the poorly soluble drugs alone. In the formulation of controlled release product microcapsule of glibenclamide BCS class II anti diabetic drug to achieve slow, controlled and complete drug release in $24 \mathrm{~h}$ for once a day administration.

\section{ACKNOWLEDGEMENTS}

The authors acknowledged Sri. C. Gangi Reddy, Secretary, Annamacharya College of Pharmacy, Rajampet for their support and encouragement for successfully completion of this research work.

\section{REFERENCES}

1. A. Kondo, Microcapsule Processing and Technology, Marcel Dekker, Inc., New York, p. 18 (1979).

2. S.K. Dash, A.S. Khan, S. R. Das, A. Padhan, D. Rout and B.C. Behera, Int.. J. Pharm. Sci. Res., 3, 1433 (2012).

3. S. Mutalik and N. Udupa, J. Pharm. Pharm. Sci., 8, 26 (2005).

4. Y.G. BachhavV.B. Patravale. Y.G. Bachhav and V.B. Patravale, AAPS PharmSciTech, 10, 482 (2009).

5. A.A. Attama and O. J. Nwabunze, Acta Pharm., 57, 161 (2007).

6. L. Si-Nang, P.F. Carlier, P. Delort, J. Gazzola and D. Lafont, J. Pharm. Sci., 62, 452 (1973).

7. K.P.R. Chowdary and P. Dwarakanadha Reddy, Int. J. Pharm. Sci. Res., 3, 360 (2012). 